\title{
SELECTED ISSUES ON DIETARY SUPPLEMENTS: THEORY AND PRACTICE
}

\author{
Marek Stych ${ }^{1}$, doctor of law \\ ${ }^{1}$ Institute of Law, Administration and Economics, Faculty of Political Sciences, Pedagogical University of Cracow, \\ Poland
}

\begin{abstract}
Dietary supplements, that is agents used to supplement the regular diet, have recently become very popular among people. Nowadays, they are used as substitutes of valuable components of the well-balanced diet rather than just its supplements. Compared to previous years, the statistical data indicate an upward trend in the consumption of such products. At the same time, more and more dietary supplements are being sold via means of remote communication (the Internet). The changes in legal regulations regarding this area deserve to be discussed.
\end{abstract}

Key words: dietary supplements, health safety, diet. JEL code: K49.

\section{Introduction}

Rationale for the choice of topic: dietary supplements have been extremely popular in the society recently. They are more and more often used as substitutes of valuable components of the wellbalanced diet rather than just its supplements. Compared to previous years, the statistical data indicate an upward trend in the consumption of such products. At the same time, more and more dietary supplements are being sold via the Internet. Therefore, their increased consumption and the changes in legal regulations constitute grounds for a discussion.

Aim: to present selected aspects related to dietary supplements in the EU and national law. The study confines to the concept of dietary supplements and their labelling rules. The practical aspect concerns their use.

Methods: Two research methods have been applied in the article: the dogmatic and legal, and the empirical (a diagnostic survey); technique used: survey; tool used: questionnaire.

Conclusions: Evaluation of the existing regulations and the results of the questionnaires. The paper ends with de lege ferenda suggestions.

\section{Definition of dietary supplement}

The term "dietary supplement" is undoubtedly specialist. Its definition can be found in the law. Dietary supplements are foodstuffs and must comply with the definition of food stipulated in the Regulation (EC) No 178/2002, according to which "food" (or "foodstuff") means any substance or product, whether processed, partially processed or unprocessed, intended to be, or reasonably expected to be ingested by humans." The definition provided for in the Act on food and nutrition safety defines dietary supplement as "a foodstuff whose aim is to supplement the normal diet, and which is a concentrated source of vitamins or minerals, or other substances with nutritional or other physiological effects, single or complex, distributed in a dosage form (...), except the products that have the properties of medicinal products within the meaning of pharmaceutical law."

In light of the quoted regulations, dietary supplements are undoubtedly considered food. Similrly to other products in this category (for example bread, dairy products or vegetables), they contain certain nutrients, though present in a more concentrated form. What differentiates dietary supplements from other food products are their relatively diverse forms, for instance: capsules, pills, tablets, lozenges, powder sachets, liquid ampoules, dropper bottles and other similar forms of liquids or powders intended to be taken in small measured quantities.

1 email: marek.stych@up.krakow.pl 
In order to correctly understand the definition itself, it is necessary to determine the purpose of use. Dietary supplements are administered to supplement the normal diet or its possible deficiencies. Unfortunately, attempts are currently being made to expand the dietary supplements market by suggesting that their composition, form of administration and purpose make them equivalent or alternative to medicines (Tomaszewska M., 2014).

It should be emphasized that medicinal products and prescription and non-prescription medicines are the products whose curative or prophylactic effect has been confirmed by tests and proven in the registration procedure.

When it comes to dietary supplements, they may have a certain physiological effect on the body, but they do not cure or prevent diseases. It is assumed that they supplement one's normal diet with vitamins, minerals or other substances that have a nutritional or other physiological effect in order to:

- maintain,

- sustain,

- facilitate,

- optimize

physiological effects.

As regards the EU and national legislation, No documentation confirming the quality and declared effects is required, which should be criticized.

\section{Labelling}

Labels are at the moment the most important and direct way of providing consumers with food information. The information on labels should be legible and, above all, simple and clear to the ordinary/typical consumer. In practice, consumers happen to find it difficult to read labels due to their small size and a large number of information required by the law. The legal basics of labelling have been stipulated in the Directive 2000/13/EC. Its numerous amendments by other acts, e.g. Directive 2003/89/EC, Regulation (EC) No. 1924/2006, or Commission Directive 2007/68/EC, testify to the necessity of adjusting such regulations to the changing reality of the dietary supplements market.

The relatively large diversity of dietary supplements undoubtedly requires an individual approach to creating their labels, both in terms of form and type of information. The knowledge of how to use dietary supplements is of fundamental importance to the consumer and to the producer. The widespread consumption of dietary supplements poses a significant problem nowadays, which is not conforming to the information on the label (Dudzik J., 2016).

The European regulations binding in the Republic of Poland, and their executory provisions, thoroughly stipulate the labelling requirements. Proper labelling can be problematic when the manufacturer wants to emphasize what distinguishes their product from others. The unit packaging of a dietary supplement is to contain the following data [RIV, i.e. the Reference Intake Value laid down in Regulation No. 1169/2011].

1) Name and identification data of the producer or distributor (based on the Community territory);

it is to enable consumers to recognize the dietary supplement and to help them distinguish it from others which the product is similar to. In order to distinguish the supplement from others, descriptive information should be placed near its name. Its market name must not mislead potential consumers, for example about its origin or other essential features such as quality, ingredients, manner of 
manufacture, or nutritional value. Information such as the name, address and, if appropriate, code of the producer, packer or vendor (based in the Community) is intended to ensure proper identification of the supplement's producer or the company placing it on the market, and the country of origin.

2) List of ingredients [Article 6 Paragraph 2 of the Directive 2000/13/EC] and quantities of certain ingredients or categories of ingredients [Article 7 of the Directive 2000/13/EC];

pursuant to Article 6 Paragraph 4a) of the Directive 2000/13/EC, "Ingredient" is any substance, including additives, used in the manufacture or preparation of a foodstuff and still present in the finished product, even if in altered form. The principle has been adopted in the EU regulations that the mandatory element of a label is a list of ingredients and quantities of some ingredients or categories of ingredients. They are given in the descending order of weight, according to the quantity used during production. The list should be preceded by the word "ingredients". Concentrated ingredients are given in their original quantity, while the additions of water or unsTable products are listed in the order of their weight in the finished product.

As regards the ingredients belonging to one of the categories contained in Annex I to the Directive $2000 / 13 / E C$, i.e. starch, oil, or milk proteins, they may be identified on the label by the names of those categories but with additional information if required by the legislator. For example, the use of the category "starch" must be complemented by its origin if that ingredient could contain gluten.

3) Net quantity or net weight and number of pieces in the case of pre-packaged dietary supplements;

pursuant to Article 8 Paragraph 1 of the Directive 2000/13/EC, the net quantity of pre-packaged dietary supplement should be expressed in:

- units of volume in the case of liquids,

- mass units,

using the litre, centilitre, millilitre, kilogram or gram, as appropriate.

Community or national provisions applicable to certain specified foodstuffs may derogate from this rule.

If a given ingredient of a dietary supplement can perform various functions, the label should inform about the function that is relevant in a given case. Quantity of an ingredient is declared if this ingredient or a category of ingredients is a part of the product's name, or it is pointed to on the label in a verbal, pictorial or graphic way, or constitutes a distinctive element (Judgment of CJEU, C446/08). The indicated quantity of the main ingredient, expressed as a percentage, corresponds to its quantity at the time of its use. Community provisions allow, under certain conditions, for derogations from this principle [Article 7 of the Directive 2000/13/EC].

Dietary supplement labels must contain information on food ingredients classified as potential allergens. The provisions ordering information about allergens to be placed on the labels entered into force in the Member States on 25 November 2005 [Directive 2003/89/EC].

4) Health claim;

e.g. 02 - "Biotin helps to maintain normal psychological functions"; 05 - "Melatonin helps to reduce the time needed to fall asleep"

[http://ec.europa.eu/food/safety/labelling_nutrition/claims/register/resources/docs/claims_pending .pdf, accessed: 20/12/2018]. Health claim is any statement, suggestion or implication that there is a relationship between health and a food category, particular food or one of its ingredients (e.g. Skrzydlo-Tefelska E., 2016). They are evaluated by the European Food Safety Authority (EFSA). If a positive opinion is obtained, the approval is made by the European Commission. The Commission 
decides whether to enter or refuse to enter a given claim in the EU register of approved health claims [Regulation (EC) No. 1924/2006].

5) Minimum durability;

pursuant to Article 9 of the Directive 2000/13/EC the date of minimum durability of a foodstuff is the date until which the foodstuff retains its specific properties when properly stored. In practice, the date is preceded by the words:

- "Best before ...", when the date indicates the day,

- "Best before end...", in other cases.

As regards the above notation, it can be referred to:

- the date itself,

- the place where the date is given on the labelling.

The "expiry date" or the date of "minimum durability" should be recorded in the following order: day, month, year. Bearing in mind the varying levels of the potential consumers' awareness, the date cannot be coded. The manner of indicating the date depends on the durability of a dietary supplement. If its durability does not exceed 3 months, only the day and the month can be provided. When the durability is from 3 to 18 months, only the month and the year can be indicated. For the product durability exceeding 18 months, it is only necessary to give the year.

One example of the derogation from the above rule is Article 9 Paragraph 5 of the Directive 2000/13/EC. This provision allows other types of date indication if Community regulations so provide.

6) Storage and use;

It is mandatory to place information about storage conditions on the label of a dietary supplement with definite durability The producer should explain how to handle the supplement:

- whether to store it below or above a certain temperature,

- whether to keep it in a refrigerator after opening,

- whether to keep it away from light.

The information on how to prepare or use a supplement is placed on its label in order to avoid inappropriate application.

As regards the Polish law, this matter has been regulated in the Regulation of the Minister of Health of 9 October 2007 on the composition and labelling of dietary supplements [Journal of Laws of 2018, item 1951].

Taking into account the high degree of public interest in dietary supplements, the lack of legal requirements concerning the content of the leaflet should be assessed critically. In practice, the packaging of these products often do not contain leaflets. If they do, however, the leaflets usually contain information about indications and dosage, warnings that the product should not be used during pregnancy and breastfeeding, and information about other commercially available supplements.

\section{Research}

The research concerned the opinion of the residents of Opole ${ }^{1}$ (a provincial/voivodeship city in the south of Poland) on the subject of dietary supplements. The survey was conducted in October and November 2018 on a group of 1,000 anonymous people over the age of 18 . The aim of the survey was to determine why dietary supplements are used, as well as to find out what opinion residents hold about such products.

1 According to GUS (Central Statistical Office) data as of 31 December 2017, the city had 128,140 inhabitants. 
The questionnaire particulars included:

1. age:

- 18 - 30 years old - 452 respondents ( $45.2 \%)$;

- 31 - 50 years old -481 respondents ( $48.1 \%)$;

- above 50 years old - $67(6.7 \%)$;

2. sex:

- women - 500 respondents (50\%);

- men - 500 (50\%);

3. employment:

- studying - 212 respondents ( $21.2 \%)$;

- white-collar worker - 143 respondents (14.3\%);

- manual worker - 187 (18.7\%);

- not working - 356 (35.6 \%);

- pensioner/retiree - 102 (10.2\%).

All the respondents indicated the administrative boundaries of the city of Opole as their place of residence.

The survey consisted of 10 closed and semi-open questions.

The first question was: "Do you take diet supplements?"

882 respondents ( $88.2 \%)$ replied "yes". 118 respondents ( $11.8 \%)$ replied "no".

According to the answers received, the vast majority of respondents use such products.

The second question was: "Why do you use dietary supplements?"

This question was semi-open, thus respondents had a choice:

a) to strengthen the organism;

b) to prevent infection;

c) to feel better;

d) to look better;

e)

The obtained results allow to conclude that the respondents primarily want to strengthen their body (383 respondents, $38.3 \%$ ) and overcome the lack of energy. 279 people $(27.9 \%)$ want to protect themselves against infection. Other important factors affecting the decision to take a dietary supplement are:

- appearance improvement - $109(10.9 \%)$;

- well-being improvement - 89 (8.9\%).

In the semi-open question some of the respondents also pointed to:

- TV advertising - 78 respondents (7.8\%);

- fashion - 62 people $(6.2 \%)$.

Third question: "How often do you use dietary supplements?"

The respondents could choose from the following answers:

a) Regularly - every day or several times a week;

b) From time to time - several times a month;

c) Occasionally - seasonally.

As can be seen from the answers received, the use of supplements by the inhabitants of Opole varies. A relatively large number of respondents $(44.8 \%)$ use them from time to time, but on the other hand, 421 residents $(42.1 \%)$ take them regularly. The smallest number of respondents use 
them sporadically - $131(13.1 \%)$. The answers obtained from the respondents lead the following conclusion: a significant number of them abuse supplements. This may be explained twofold. The residents either eat meals poor in nutrients and vitamins, or they have low awareness of the effects of the excessive use of dietary supplements and their dangerous combinations.

The fourth question: "Do you use dietary supplements as an alternative to medicines?" Respondents had two choices:

a) Yes;

b) No;

Unfortunately, the obtained results are very worrying, for as many as 735 respondents $(73.5 \%)$ admitted treating supplements as substitutes for medicines. This shows a dangerous tendency towards giving up medicines in favour of foodstuffs, that dietary supplements actually are. This dangerous phenomenon is gaining in importance and results from two main reasons:

- the respondents lack the knowledge necessary to distinguish between medicines and dietary supplements;

- the advertisements and commercials are trying to put the equal sign between medicines and dietary supplements.

The fifth question: "Do you use one dietary supplement or several at the same time?"

The respondents had two choices:

a) One type;

b) Two Types;

c) Several types.

Similarly, as before, the results obtained should be assessed negatively, because:

- 452 respondents use two types of dietary supplements (45.2\%);

- 387 respondents use one type (38.7\%);

- 161 respondents take several types of supplements (16.1\%).

The sixth question: "Where do you purchase dietary supplements?"

The answers to choose from were as follows:

- traditional pharmacies;

- online pharmacies;

- the Internet;

- general shops.

As far as the place of purchase is concerned, the traditional way of purchasing dietary supplements was declared by 640 respondents (64\%). Only 73 of them (7.3\%) buy such products from online pharmacies. 120 respondents $(12 \%)$ declared buying supplements from general shops. Unfortunately, as the results of the survey indicate, some people showed No responsibility in choosing where to buy dietary supplements, for 167 respondents $(16.7 \%)$ purchase them online without paying attention to who sells them. This is due to the low awareness about the dangers associated with purchasing supplements that have not been legally approved for marketing on the Polish market.

The seventh question: "Where do you look for information about dietary supplements?"

The respondents could choose from one of the following answers:
a) The Internet - google search engine;
b) Websites about health;
c) TV;
d) Paper magazines. 
As the respondents indicated, it is the Internet that they search for information about dietary supplements most often. They do so by typing their names or some key words into the search engine. This option was preferred by 724 respondents $(72.4 \%)$. The smallest number of the respondents, because only 63 people $(6.3 \%)$, pointed to paper magazines as a source of information about supplements. TV as a source of information about these products was chosen relatively often, i.e. by 213 respondents $(21.3 \%)$.

The eighth question: "What are you guided by when choosing the type of dietary supplement?"

The respondents chose from the following:
a) Previous experience;
b) Pharmacist's recommendation;
c) Low price;
d) Advertisement;
e) Brand.

When making a decision which supplement to buy, the surveyed residents are guided by numerous factors, but it is their own experience that turned out to be the most important for 380 of them (38\%). The second most important factor was pharmacist's recommendation, indicated by 297 respondents (29.7\%). Low price was important for 159 respondents (15.9\%). The influence of advertising was indicated by a similar number of respondents, that is $144(14.4 \%)$.

Only 20 respondents $(2 \%)$ admitted taking the brand into account when choosing a dietary supplement.

The ninth question: „Did the use of dietary supplements bring the expected results?"

The above question is of crucial importance for the conducted research. Are Poles satisfied with the dietary supplements they use? The survey showed that yes, but the level of satisfaction is not very high. According to 556 respondents $(55.6 \%)$, the supplements they had used produced an effect, though they had expected it would be higher. At the same time, 383 respondents ( $38.3 \%)$ had No objections to the effect of the purchased supplements. Only 61 people $(6.1 \%)$ did not notice any improvement during the use of such products.

The tenth question: "What do you think dietary supplements are?"

The respondents had two choices:

a) equivalents of medicines,

b) food,

c) agents that supplement one's diet (vitamins).

According to the EU and the national legislators, dietary supplements are not medicines, but supplements to the diet, composed of nutrients. As the survey has shown, 460 consumers ( $46 \%$ ) are aware of this. Only $20 \%$ of the respondents identified such products as medicaments. What is more, $59 \%$ of the study participants believe that the effect of dietary supplements must be confirmed by scientific research.

\section{Conclusions}

It must be emphasized that, despite the size of supply and consumption, there is practically No supervision over the dietary supplements market from Sanitary Inspection bodies. In the legal situation as of today, everyone can introduce a supplement into the market by only declaring its composition to sanitary bodies by means of the so-called notification. The Polish market is particularly vulnerable to unfair market practices that infringe upon the collective interests of consumers. 
De lege ferenda suggestions:

1. it is necessary to regulate the dietary supplements industry,

2. advertising of supplements should be restricted, for example by banning the broadcast of advertisements that violate the law,

3. the industry's self-regulation should be the core of the legal changes,

4. in order to ensure the safety of the citizens, the requirements regarding dietary supplements should be equalized with the requirements regarding medicines,

5. supplements should have a clearly separate place in pharmacies, provided that they are considered special foods,

6. a special authority called "food police" should be established.

\section{References}

1. Dudzik, J. (2016). Oznakowanie i reklama zywnosci w prawie Unii Europejskiej - wybrane zagadnienia zwiazane z wejsciem w zycie rozporzadzenia nr 1169/2011 (Labelling and advertising of food in the European Union law - selected issues related to the entry into force of the Regulation No. 1169/2011). Europejski Przeglad Sadowy. No. (2), pp. 10-15.

2. Tomaszewska, M. (2014). Suplement diety a lek (Dietary supplement vs medicine). Przeglad Prawniczy Uniwersytetu Warszawskiego. No. (2), pp.92-103.

3. Skrzydlo-Tefelska, E. (2016). Oswiadczenia zywieniowe i zdrowotne w prawie Unii Europejskiej a znaki towarowe (Nutrition and health claims in the European Union law and trademarks) Europejski Przeglad Sadowy. No. (2), pp. 4-9.

4. Judgment of the Court of Justice of the European Union of 29 April 2010, C-446/08, Approximation of the laws of the Member States relating to food supplements (Solgar et al.). Legalis.

\section{Legal acts}

1. Regulation (EC) No 178/2002 of the European Parliament and of the Council of 28 January 2002 laying down the general principles and requirements of food law, establishing the European Food Safety Authority and laying down procedures in matters of food safety (OJ $2002 \mathrm{~L} 31$, p. Journal of Law WE L 31, p. 1).

2. The Act on Food Safety and Nutrition of 25 August 2006 (Journal of Laws Laws of 2018, item 1541).

3. Directive 2000/13/EC of the European Parliament and of the Council of 20 March 2000 on the approximation of the laws of the Member States relating to the labelling, presentation and advertising of foodstuffs (OJ L $109,6.5 .2000$, p. 29).

4. Directive 2003/89 / EC of the European Parliament and of the Council of 10 November 2003 amending Directive 2000/13 / EC as regards the determination of ingredients present in foodstuffs, (OJ L 308, 25.11.2003 pp. 0015 - 0018).

5. Regulation (EC) No 1924/2006 of the European Parliament and of the Council of 20 December 2006 on nutrition and health claims made on foods (OJ L 404/9, 30.12.2006).

6. Commission Directive 2007/68/EC of 27 November 2007 amending Annex IIIa to Directive 2000/13/EC of the European Parliament and of the Council as regards certain food ingredients (OJ L 310/11, 28.11.2007).

7. Regulation (EU) No 1169/2011 of the European Parliament and of the Council of 25 October 2011 on the provision of food information to consumers, amending Regulations (EC) No 1924/2006 and (EC) No 1925/2006 of the European Parliament and of the Council, and repealing Commission Directive 87/250/EEC, Council Directive 90/496/EEC, Commission Directive 1999/10/EC, Directive 2000/13/EC of the European Parliament and of the Council, Commission Directives 2002/67/EC and 2008/5/EC and Commission Regulation (EC) No 608/2004 (OJ L 304/18, 22.11.2011).

8. Directive 2003/89/EC of the European Parliament and of the Council of 10 November 2003 amending Directive 2000/13/EC as regards indication of the ingredients present in foodstuffs (OJ L 308, 25.11.2003 pp. 0015 - 0018).

9. Regulation (EC) No 1924/2006 of the European Parliament and of the Council of 20 December 2006 on nutrition and health claims made on foods (OJ L 404/9 of 30.12.2006).

10. Regulation of the Minister of Health regarding the composition and labelling of dietary supplements of 9 October 2007 (i.e. Journal of Laws of 2018, item 1951). 